\title{
SYSTEMATIC LITERATURE REVIEW OF SOFTWARE PROCESS IMPROVEMENT MODELS IN SMALL COMPANY
}

\author{
Sujiliani Heristian ${ }^{1}$, Wati Erawati ${ }^{2}$ \\ ${ }^{1}$ STMIK Nusa Mandiri \\ Jl. Kramat Raya No.18 \\ ${ }^{2}$ Universitas Bina Sarana Informatika \\ Jl. R.S Fatmawati No.24 Pondok Labu \\ ${ }^{1}$ sujilianiheristian30@gmail.com, ${ }^{2}$ wati.wti@bsi.ac.id
}

\begin{abstract}
Abstrak - Berkembangnya perangkat lunak dalam organisasi besar maupun kecil saat ini mendorong untuk organisasi tersebut melakukan pengembangan dan pengontrolan dalam hal tersebut, dalam hal ini perusahaan kecil pun melakukan pengontrolan dari software yang dimiliki. Akan tetapi perusahaan kecil pengontrolan dari manajemen pengembangan perangkat lunak dan struktur masih merupakan tantangan utama. Dalam hal ini Software Proses Improvement (SPI) meliputi penilaian dan peningkatan proses dan praktek yang terlibat dalam pengembangan perangkat lunak salah satu model yang dapat digunakan adalah CMMI. CMMI dapat digunakan dalam organisasi yang ingin mengukur dari kemampuan perangkat lunak, system, atau bahkan rekayasa produk dan dapat berpartisipasi dalam penilaian akan tetapi setelah dilakukan sistematik literature ini dapat di tarik kesimpulan bahwa CMMI kurang tepat untuk perusahaan kecil.
\end{abstract}

Keywords - Systematic Literature Review, Software Process Improvement Models.

Abstract- The development of software in large and small organizations is currently encouraging for these organizations to develop and control in this case, in this case small companies also control the software they have. However, small control companies from software development management and structure are still the main challenges. In this case the Software Process Improvement (SPI) includes the assessment and improvement of the processes and practices involved in software development. One of the models that can be used is CMMI. CMMI can be used in organizations that want to measure software capabilities, systems, or even product engineering and can participate in assessments but after systematic literature this can be concluded that CMMI is not right for small companies.

Keywords — Systematic Literature Review, Software Process Improvement Models.

\section{PENDAHULUAN}

Perkembangan perangkat lunak dalam organisasi maupun perusahaan saat ini tidak hanya pada perusahaan besar akan tetapi dilakukan di perusahaan atau organisasi yang berskala kecil. Namun dalam perusahaan kecil pengontrolan dari manajemen pengembangan perangkat lunak dan struktur masih merupakan tantangan utama[1][2] dan dalam melakukan evaluasi dari perangkat lunak itu sendiri masih memiliki kesulitan dikarenakan kurang memadai[3]. Untuk saat ini banyak dari perusahaan kecil yang memulai pengembangan perangkat lunak yang berkualitas[[4]. Dalam hal ini Software Proses Improvement (SPI) meliputi penilaian dan peningkatan proses dan praktek yang terlibat dalam pengembangan perangkat lunak[6].SPI itu sendiri memiliki beberapa model yang diantaranya CMMI, ISO, SCAMPI, PMBOK, SPICE, SCRUM dan lainnya[7][6][8].

Model yang banyak dibahas oleh penelitian yang lain dan model yang dapat digunakan didalam perusahaan kecil merupakan model seperti CMMI
(Capability Maturity Model Integration)[9][10] yang dimana memungkinkan dapat digunakan dalam perusahaan kecil dalam hal ini penulisan ini mencari kebenaran dalam hal tersebut. Model CMMI ini merupakan hasil dari evolusi CMM[11][12] yang dimana CMM dan CMMI menunjukkan organisasi dapat dinilai untuk tingkat yang lebih tinggi yaitu dapat meningkatkan kemampuan untuk menyampaikan dari jadwal, biaya dan kualitas[13]. CMMI dapat digunakan dalam organisasi yang ingin mengukur dari kemampuan perangkat lunak, system, atau bahkan rekayasa produk dan dapat berpartisipasi dalam penilaian dan CMMI memiliki 5 tingkatan yaitu tingkat pertama initial, tingkat kedua repeatable, tingkat tiga defined, tingkat empat managed dan tingkat kelima optimizing[4][14]. Disini CMMI dapat meningkatkan dari kinerja organisasi tersebut[15].

Pada organisasi kecil CMMI sudah mulai diterapkan pada tahun 2001 di 13 lokasi Australia, dimana sebanyak $33 \%$ mengalami penurunan dalam biaya perbaikan cacat, pengurangan $50 \%$ dalam waktu untuk pengiriman rilis kemampuan untuk mengkonfigurasi membangun meningkat; 
pengurangan $60 \%$ dalam penyusunan, pelaksanaan, dan ulang bentuk pre-test untuk audit post-test[12].

Dengan adanya hal diatas apakah model CMMI benar-benar tepat digunakan untuk organisasi kecil yang dimana dalam penelitian yang dilakukan oleh Khokhar sebagian besar organisasi tidak menerapkan model CMMI dikarenakan CMMI tidak layak untuk organisasi kecil[6]. Penulisan ini melakukan sistematis literature review (SLR) untuk mengetahui kesesuaian SPI model CMMI untuk organisasi kecil, disini penulis melakukan penelitian dari CMMI tersebut.

\section{TINJAUAN PUSTAKA}

Pendekatan dari sistematis literature tentang model software process improvement di organisasi kecil khususnya model CMMI yang dipilih. SLR ini merupakan proses mengidentifikasi, menilai dan menafsirkan bukti dari penelitian yang ada bertujuan untuk memberikan jawaban pertanyaan-pertanyaan penelitian yang spesifikasi[16][17].

Seperti dalam gambar 1 dimana ditunjukkan bahwa SLR ini melakukan tiga tahapan: perencanaan, pelaksanaan dan pelaporan tinjauan literature. Langkah pertama mengidentifikasi yang merupakan syarat dari review sistematis. Untuk tujuan dari tinjauan literature akan dibahas pada pendahuluan bab ini. Selanjutnya review sistematis yang ada pada model CMMI ini akan dikaji. Langkah kedua protocol dari tinjauan akan dirancang mengarahkan dari pelaksanaan review.

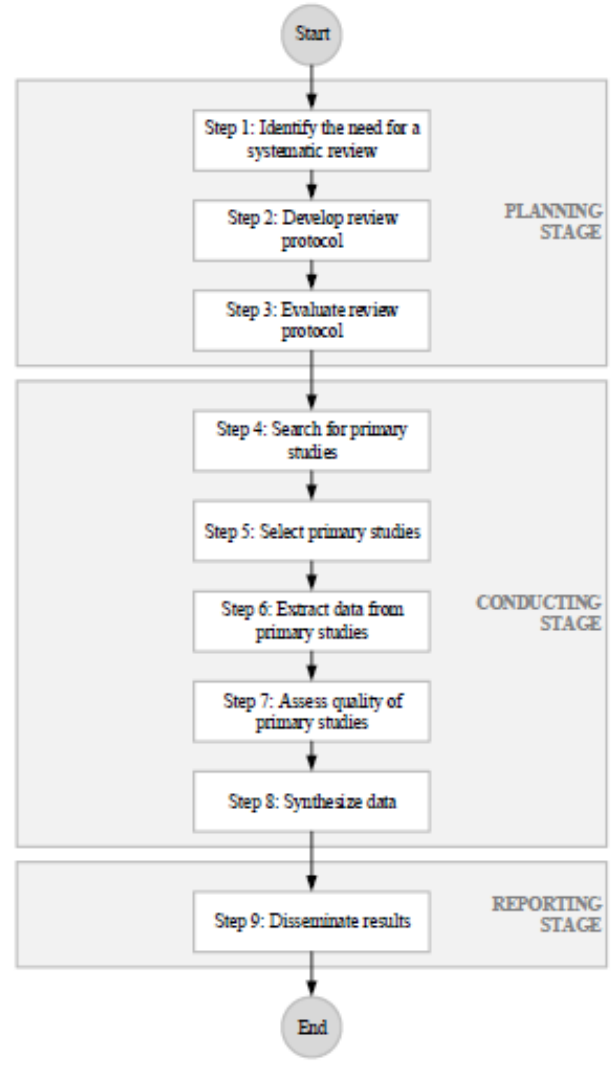

Gbr 1. Systematic Literature Review Steps

\section{PEMBAHASAN}

Pertanyaan penelitian (RQ) ditentukan agar menjaga review tetap terfokus. Tabel I akan penunjukan dari daftar pertanyaan.

TABEL I

PERTANYAAN PENELITIAN SYSTEMATIC REVIEW

\begin{tabular}{|c|c|c|}
\hline ID & Question & Aim \\
\hline RQ1 & $\begin{array}{l}\text { What types of } \\
\text { evaluation strategies } \\
\text { are used to evaluated } \\
\text { CMMI initiatives? }\end{array}$ & $\begin{array}{l}\text { To identify which } \\
\text { concrete evaluation } \\
\text { strategies are used } \\
\text { and how they are } \\
\text { applied in practice to } \\
\text { assess CMMI } \\
\text { initiatives }\end{array}$ \\
\hline RQ2 & $\begin{array}{l}\text { What are the reported } \\
\text { metrics for } \\
\text { evaluating the CMMI } \\
\text { initiatives? }\end{array}$ & $\begin{array}{l}\text { To identify the } \\
\text { metrics which are } \\
\text { commonly collected } \\
\text { and used to evaluated } \\
\text { CMMI initiatives }\end{array}$ \\
\hline RQ3 & $\begin{array}{l}\text { What measurement } \\
\text { perspectives are used } \\
\text { in the evaluation and } \\
\text { to what extent are } \\
\text { they associated with } \\
\text { the identified CMMI } \\
\text { initiatives? }\end{array}$ & $\begin{array}{l}\text { To determine } \\
\text { which measurement } \\
\text { perspective CMMI } \\
\text { initiatives } \\
\text { evaluated. } \\
\text { Furthermore, } \\
\text { analyzed to } \\
\text { relationship between } \\
\text { CMMI initiatives and } \\
\text { measurement } \\
\text { perspectives }\end{array}$ \\
\hline RQ4 & $\begin{array}{l}\text { What are the } \\
\text { confounding factors } \\
\text { in relation to the } \\
\text { identified evaluation } \\
\text { strategies? }\end{array}$ & $\begin{array}{l}\text { To identify the } \\
\text { reported factors that } \\
\text { can distort and hence } \\
\text { limit the validity of } \\
\text { the results of the } \\
\text { CMMI evaluation. } \\
\text { To determine if these } \\
\text { issue are addressed } \\
\text { and to identify } \\
\text { possible remedies. }\end{array}$ \\
\hline
\end{tabular}

\section{A. Strategi Pencarian}

Pada proses ke empat ini yaitu proses pencarian yang terdiri dari beberapa kegiatan, dari memilih perpustakaan digital mengidentifikasikan string pencarian, mengeksekusi pencarian contoh, menyempurnakan string pencarian dan mengambil daftar awal dari studi utama dari perpustakaan digital yang cocok dengan string pencarian. Sebelum memulai pencarian, set yang tepat dari database harus dipilih untuk meningkatkan kemungkinan menemukan artikel yang sangat relevan. Database sastra paling populer di lapangan dicari untuk memiliki set luas studi mungkin. Sebuah perspektif yang luas diperlukan untuk cakupan luas dan luas literature dalam hal ini penulis menggunakan satu perpustakaan digital untuk mencari jurnal terkait yaitu peneliti menggunakan IEEE Explore (ieeexplore.ieee.org). 
String dalam pencarian penulis sesuai dengan langkah-langkah berikut:

1. Identifikasi istilah pencarian dari pertanyaan penelitian

2. Identifikasi istilah pencarian dalam judul yang relevan, abstrak dan kata kunci

3. Identifikasi sinonim, ejaan alternatif dan antonim dari istilah pencarian

\section{B. Seleksi Studi}

Kriteria inklusi dan eksklusi digunakan dalam pemilihan studi utama. Kriteria ini ditunjukkan pada Tabel II

TABEL II

INKLUSI DAN KRITERIA EKSKLUSI

\begin{tabular}{|l|l|}
\hline \multirow{3}{*}{$\begin{array}{l}\text { Kriteria } \\
\text { inklusi }\end{array}$} & $\begin{array}{l}\text { Studi di industri menggunakan data } \\
\text { besar dan kecil set skala }\end{array}$ \\
\cline { 2 - 3 } & $\begin{array}{l}\text { Studi membahas dan kinerja } \\
\text { pemodelan di bidang software process } \\
\text { improvement mode CMMI Untuk studi } \\
\text { yang memiliki versi kedua }\end{array}$ \\
\cline { 2 - 2 } & $\begin{array}{l}\text { konferensi dan jurnal, hanya versi } \\
\text { jurnal akan dimasukkan Untuk } \\
\text { duplikat publikasi dari studi yang } \\
\text { sama, hanya yang paling lengkap dan } \\
\text { terbaru yang akan dimasukkan }\end{array}$ \\
\hline Kriteria & $\begin{array}{l}\text { Studi tanpa validasi kuat atau termasuk } \\
\text { eksklusi eksperimen Studi CMMI } \\
\text { membahas organisasi kecil }\end{array}$ \\
\hline
\end{tabular}

Software paket Mendeley digunakan untuk menyimpan dan mengelola hasil pencarian. Pada langkah 5 proses seleksi studi dikerjakan dalam dua langkah: mengesampingkan studi utama berdasarkan judul dan abstrak dan mengesampingkan studi utama berdasarkan teks lengkap. Studi literatur dan penelitian lain yang tidak termasuk hasil eksperimen dikecualikan. Tingkat kemiripan studi dengan CMMI.

Daftar akhir studi utama yang dipilih untuk tahap pertama memiliki 25 studi utama. lalu, 25 studi utama dianalisis. Selain kriteria inklusi dan eksklusi, kualitas studi utama, relevansinya dengan pertanyaan penelitian dan studi kesamaan dianggap. Penelitian serupa oleh penulis yang sama di berbagai jurnal telah dihapus. 25 studi utama tetap setelah eksklusi penelitian berdasarkan pada pemilihan teks lengkap.

\section{Ekstraksi Data}

Studi utama yang dipilih diekstraksi untuk mendapatkan data untuk mengatasi pertanyaan penelitian yang berkaitan dalam ulasan ini. Ada 25 studi utama yang dipilih, Bentuk ekstraksi data dirancang untuk mendapatkan data dari studi utama yang dibutuhkan untuk menjawab pertanyaan penelitian ini. Sifat diidentifikasi melalui pertanyaan penelitian dan analisis yang penulis harapkan dapat diperkenalkan. Tujuh properti digunakan untuk menjawab pertanyaan penelitian ditunjukkan pada Tabel III. Ekstraksi data dilakukan secara berulang.

TABEL III

EKSTRAKSI

\begin{tabular}{|l|l|l|}
\hline ID & \multicolumn{1}{|c|}{ Property } & \multicolumn{1}{|c|}{ Research question(s) } \\
\hline P1 & Research method & Overview of the studies \\
\hline P2 & Context & Overview of the studies \\
\hline P3 & CMMI initiative & RQ1, RQ2, RQ3 \\
\hline P4 & $\begin{array}{l}\text { Success indicator } \\
\text { and metric }\end{array}$ & RQ2 \\
\hline P5 & $\begin{array}{l}\text { Measurement } \\
\text { perspective }\end{array}$ & RQ3 \\
\hline P6 & Evaluation Strategy & RQ1, RQ4 \\
\hline P7 & Confouding factors & RQ4 \\
\hline
\end{tabular}

\section{Threats to Validity}

Penulisan ini untuk menganalisis studi tentang model CMMI di organisasi kecil berdasarkan software process improvment. Pencarian ini tidak didasarkan pada pembacaan manual judul semua makalah yang diterbitkan di jurnal. Ini berarti bahwa ulasan ini mungkin telah dikeluarkan beberapa tulisan software process improvment dari beberapa prosiding konferensi atau jurnal. Penulisan didapatkan juga studi dari prosiding konferensi karena lebih banyak referensi yang diterbitkan dalam prosiding konferensi.

Pada literatur ini, 25 studi utama software process improvement menunjukkan bagaimana minat dalam software process improvement telah berubah. Banyak studi yang menggambarkan dari system kerja SPI tersebut maupun CMMI. Dalam hal ini jurnal SPI maupun CMMI lebih banyak terdapat pada prosiding konferensi dibandingkan dengan jurnal.

\section{E. Topik penelitian}

CMMI didalam industry selama ini dikenal sebagai model praktik terbaik. CMMI ini memungkinkan organisasi mereka mengevaluasi dari kapasitas proses mereka, menetapkan prioritas untuk perbaikan dan membantu meningkatkan kinerja mereka[3].

Dalam hal ini proses yang digunakan di sebuah organisasi tergantung dari beberapa faktor, bias dari faktor domain aplikasi, budaya maupun struktur organisasi dan ukuran.[18][19], selain itu CMMI dapat membantu mengintegrasikan dari fungsi organisasi tradisional yang terpisah[20][21], proses dari menetapkan tujuan dan prioritas perbaikan serta memberikan bimbingan untuk proses kualitas[9][22][23].

CMMI sudah terbukti salah satunya dapat memanage software milik perusahaan yang berada di shanghai dengan cara menggunakan metode dari scoring agar dapat meningkatkan dari kematangan software[20][24].

Pada pembahasan diatas sudah dipaparkan bahwa model CMMI ini memiliki 5 tingkat yang dapat dilihat pada gambar 2[11][25]. 


\section{Maturity ladder}

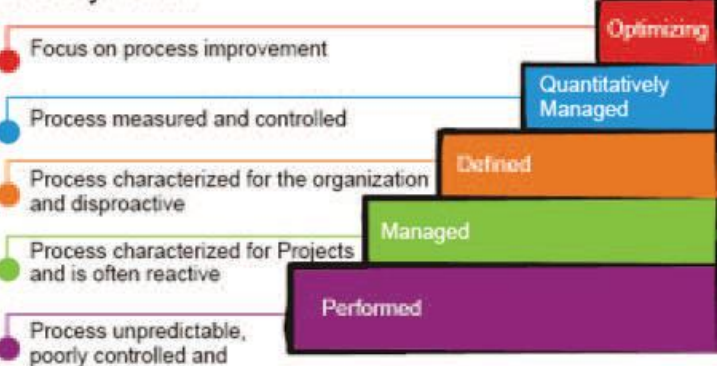

poorly controlled and

Gbr 2. CMMI Level

Level 1 - Initial - di mana proses yang informal dan keberhasilan tergantung pada kompetensi dan heroik dari personil dan bukan pada penggunaan proses terbukti, maka tingkat ini tidak memiliki tugas dan tidak dievaluasi oleh model; Level 2 - Managed menjamin manajemen proyek, persyaratan dan semua perencanaan dan eksekusi mereka; Level 3 - Defined proses mereka ditandai dengan baik dan dipahami, dan dijelaskan; Level 4 - Secara kuantitatif Dikelola memiliki tujuan kuantitatif untuk kualitas dan kinerja proses; Level 5 - Dioptimalkan - di mana proses yang terus menerus ditingkatkan berdasarkan pemahaman sejarah yang ditunjukkan pada gambar 2. Setiap tingkat CMMI terdiri oleh sekelompok area proses, di mana masing-masing wilayah terdiri dari satu set praktek yang saling terkait. Ketika diimplementasikan secara kolektif, yaitu semua praktek dari area proses ditentukan, mereka memenuhi tujuan yang signifikan untuk tingkat. Area proses menggambarkan aspek dari setiap proses, tetapi tidak menjelaskan bagaimana proses yang efektif dijalankan. Ini berarti Tingkat kematangan menyediakan cara mengendalikan dan penataan kinerja organisasi dalam disiplin tertentu atau mengatur disiplin dan didefinisikan dengan baik tahap evolutif, di mana setiap tingkat menetapkan bagian penting dari proses.

\section{KESIMPULAN}

Dalam penelitian ini menyajikan tinjauan literatur sistematis yang menyelidiki bagaimana CMMI pada organisasi kecil diukur dan dievaluasi. Tujuannya adalah untuk mengidentifikasi dan mengkarakterisasi pendekatan yang berbeda yang digunakan dalam pengaturan yang realistis, yaitu, untuk memberikan garis besar dan diskusi strategi evaluasi dan pengukuran yang digunakan di lapangan untuk menilai inisiatif perbaikan yang komprehensif. Seperti yang sudah di jelaskan CMMI merupakan model yang biasa digunakan dan baik dalam peningkatan software banyak juga penelitian yang sudah membahas hal tersebut dikarenakan kondisi perusahaan saat ini membutuhkan model dari SPI tersebut. Akan tetapi setelah peneliti melakukan penelitian kurangnya pembahasan yang membahas CMMI untuk organisasi kecil itu dikarenakan adanya ketidakcocokan dalam hal penerapan CMMI untuk organisasi kecil.
Diharapkan dengan adanya hasil ulasan ini bisa ditemukannya cara untuk penerapan CMMI di organisasi kecil.

\section{REFERENSI}

[1] X. Larrucea, R. V. O. Connor, R. Colomo-palacios, and C. Y. Laporte, "Software Process Improvement in Very Small Organizations," in IEEE Software, 2016, no. April, pp. 85-89.

[2] G. V. Boas and A. Regina, "An approach to implement software process improvement in small and mid-sized organizations," in Seventh International Conference on the Quality of Information and Communications Technology An, 2010, pp. 447-452.

[3] S. Trudel and J. L. M. Par, "PEM: The small companydedicated software process quality evaluation method combining CMMI SM and ISO / IEC 14598," in Software Qual, 2006, pp. 7-8.

[4] Z. Lina and S. Dan, "Research on Combining Scrum with CMMI in Small and Medium Organizations," in International Conference on Computer Science and Electronics Engineering, 2012, pp. 554-557.

[5] M. Unterkalmsteiner et al., "Evaluation and Measurement of Software Process Improvement - A Systematic Literature Review," 2012, vol. 38, no. 2, pp. 398-424.

[6] M. N. Khokhar and A. Rauf, "MECA: Software Process Improvement for Small Organizations," in IEEE, 2010, pp. 16.

[7] S. Choi, D. Kim, and S. Park, "ReMo: A Recommendation Model for Software Process Improvement," 2012, pp. 135139.

[8] A. Kang and L. Barolli, "CMMI Security Model for Cloud Manufacturing System's Network," in Eighth International Conference on Broadband, Wireless Computing, Communication and Applications, 2013, pp. 449-452.

[9] L. Zhang and D. Shao, "Software Process Improvement for Small and Medium Organizations Based on CMMI," in IEEE, 2011, pp. 2402-2405.

[10] D. Falessi, M. Shaw, and K. Mullen, "Achieving and Maintaining CMMI Maturity Level 5 in a Small Organization," in IEEE Software.

[11] M. A. S. Miyashiro and N. S. Anna, "CMMI-DEV Process Areas Modeled on a Process for Critical Embedded Systems Development," in Science and Information Conference, 2015, pp. $870-878$.

[12] A. Omran, "AGILE CMMI from SMEs perspective," in Agile.

[13] J. Sutherland, D. Ph, and K. Johnson, "Scrum and CMMI Level 5: The Magic Potion for Code Warriors," in the 41st Hawaii International Conference on System Sciences, 2008, pp. 1-9.

[14] M. Lee, "Improvement of Performance for QMO by Correlation between SPs and GPs in CMMI Support," 2016, pp. 315-318.

[15] C. R. Jakobsen and K. A. Johnson, "Mature Agile with a twist of CMMI," in Agile, 2008, pp. 212-217.

[16] D. Radjenović, M. Heričko, R. Torkar, and A. Živkovič, "Software Fault Prediction Metrics: A Systematic Literature Review," Inf. Softw. Technol., 2013.

[17] C. G. Von Wangenheim, J. Carlo, R. Hauck, and A. Von Wangenheim, "focus 2," in I, 2009, no. April, pp. 59-67.

[18] N. Ehsan, O. A. Malik, F. Shabbir, E. Mirza, and M. W. Bhatti, "Comparative Study for PMBOK \& CMMI frameworks and identifying possibilities for integrating ITIL for addressing needs of IT service industry," in IEEE, 2010, pp. 113-116.

[19] J. Conference et al., "via Application of CMMI Measurement and Analysis," in Joint Conference of the 23nd International Workshop on Software Measurement (IWSM) and the Eighth International Conference on Software Process and Product Measurement (Mensura) A, 2013.

[20] J. Li, "Application of CMMI in Innovation Management," in IEEE, 2007, pp. 4966-4969.

[21] F. J. Pino, M. T. Baldassarre, M. Piattini, and G. Visaggio, 
"Harmonizing maturity levels from CMMI-DEV and ISO / IEC 15504," J. SOFTWAREMAINTENANCE Evol. Res. Pract., no. September 2009, pp. 279-296, 2010.

[22] Q. Ijaz and H. Asghar, "Exploratory Study to Investigate the Correlation and Contrast between ISO 9001 and CMMI Framework," in IEEE, 2016, pp. 388-391.

[23] S. W. Baker, "Formalizing Agility, Part 2: How an Agile Organization Embraced the CMMI," in Agile Confrence, 2006.

[24] J. Crisóstomo, L. Flores, and A. Dávila, "Convergence Analysis of ISO / IEC 12207 and CMMI- DEV: A Systematic Literature Review," in IEEE, 2016.

[25] Y. Kryuchkova and D. Pavlov, "Implementing Usability Methods into CMMI-Compliant Software Development Process Внедрение практик юзабилити в процесс разработки ПО в соответствии с С ММI Юлия Крючкова," in IEEE, 2010, pp. 111-116. 